\title{
The Analysis and Evaluation of Physical Education Teaching Methods under Current Status
}

\author{
Liping Hua \\ Taishan Medical University, China
}

Keywords: Physical education, teaching methods, research status, analysis and evaluation

\begin{abstract}
College students' awareness of physical exercise and establishing lifelong exercise will not only help college students to strengthen their physical fitness and gain a healthy and strong body, but also realize the ultimate goal of physical education in colleges and universities. The quality of physical education teaching methods in colleges and universities will affect the effectiveness of college students' physical exercise to a great extent. Therefore, it is of great significance to analyze the current physical education methods in Chinese universities. This article mainly analyzes the status quo of physical education teaching methods in colleges and universities, and puts forward an evaluation, so as to put forward concrete measures to improve college physical education teaching methods, in order to provide some references for college physical education reform.
\end{abstract}

\section{Introduction}

China clearly stated in the outline of the National Fitness Program: "We must educate students on life-long sports and cultivate students' awareness of physical exercise, skills, and habits. School sports are the foundation of lifelong sports and shoulder the history of cultivating students' lifelong sports consciousness. In order to achieve the connection between school sports and lifelong sports, we must liberate school sports from the traditional model, pay attention to the cultivation of students' sports consciousness, and achieve the goal of lifelong sports. With the development of the times, the national sports and lifelong sports have become a new trend of modern sports [1]. To make lifelong sports a reality, the key lies in the fact that during the student's time, we must have a good sense of sports, master the correct methods of physical exercise, and cultivate the habit of regular physical exercise.

\section{Current status of physical education teaching}

\subsection{The insufficient understanding of physical education classes by students}

In general, college students have a relatively shallow understanding of physical education classes. This is because college students are currently required to complete the heavy cultural study tasks in schools, coupled with the pressure of society and parents on their requirements for further studies, and the competition for learning is very fierce. Students only know that they are immersed in reading books and think that "participating in sports activities will waste time in learning." Therefore, the mastery of sports knowledge and sports skills is very limited, not to mention the understanding of the value and significance of physical exercise. In response to this situation, I conducted a survey of students in our school in recent years, mainly to investigate students' sports the attitude of exercise, of which $24.3 \%$ is willing, $45.2 \%$ does not matter, $31.5 \%$ are unwilling. It is common for students to take a leave of absence from a physical education class or suffer from illnesses [1]. The majority of girls are girls. The students' lack of interest in physical education directly affects the effectiveness and development of physical education.

\subsection{The weak students' sports will}

The most important physical exercise is to persevere, at present, many colleges and universities lack of perseverance in physical education exercise, often subject to personal feelings, venues, 
weather and other factors. When you are in a good mood, you will organize outdoor sports. When you are in a bad mood, you will go to study indoors. When you experience changes in the weather, especially in cold weather, you will reduce the number of exercises or simply skip exercising [2]. When the weather is hot, students hide in the shade of trees or play in the corners of the cell phone and playing cards. When they encounter difficulties, they withdraw and cannot persist. Did not develop good physical exercise habits, let alone exercise regularity. At present, college students' physical education lacks consciousness and initiative, they do not form good exercise habits, and their sports will is weak. They cannot participate in physical exercise for a long time and actively.

\subsection{The insufficient attention to physical education from colleges and universities}

The physical education class is a relaxed business in the school. When a doll takes the lead and plays, the teacher arrangement is also more casual. In order to pursue higher education rates, many schools pay little attention to school sports. The phenomenon of heavy intelligence and light weight is very serious. Some schools have shrunk their physical education courses. The more serious is that some schools have used physical education classes for other purposes [2]. During the preparation period, physical education classes are the second class of review. Extra-curricular activities have also been reduced in time. Students can only use Sunshine Sports for an hour in 8 minutes. In addition to the one-sidedness of social understanding of sports and the impact of exam-oriented education, teachers and parents also have misunderstandings about physical education.

\subsection{The insufficient investment}

Physical education classes cannot be completed by sports awareness. They require the support of venues, equipment, time, and technology and are fully integrated with practical activities. Many schools were originally occupied by various types of buildings due to their lack of space. The venues were seriously inadequate and a multi-functional basketball court was fairly good [1]. For safety reasons, dangerous objects such as shot put and javelin have been collected by museums. A large-scale sports meeting was held. Tug of war, holding the ball, and a 30-meter relay were popular. The long-distance running of more than 800 meters was listed as a prohibited item. Students could only see those ancient sports items at the Olympic Games.

\subsection{The low level of physical education teacher}

The teacher's performance in the classroom will directly affect the student's learning. Teachers who are serious in teaching, friendly in attitude, caring and loving the student are easily respected and loved by the students. If physical education teachers can always provide correct technical guidance to students, promote the improvement of students' motor skills, and make students happy in the sport, this will stimulate students' interest in sports. And these must require physical education teachers to have a comprehensive professional and technical capability. However, the current situation is not optimistic. Many physical education teachers have insufficient awareness of their ideas, lack of professional competence, lack of enthusiasm for teaching, and cannot prepare lessons well, study teaching materials, deal with problems in teaching, and do not organize sports seriously. Teaching cannot explain the demonstration correctly or even let freedom. It causes great difficulties for the students to learn [2]. Students have low learning desires and low motor skills. At the same time, during sports practice, the teachers are not correctly and effectively instructing the students. The students are in a state of blind exercise, which inevitably results in sports injuries and casts a shadow on the students.

\subsection{The lack of supervision mechanism}

The school's contempt for physical education is compelled to understand the pressure of survival. However, some education authorities have turned a blind eye to the phenomenon of compressing physical education and extracurricular activities. The storage of sports equipment is obviously inadequate, and the lack of sports does not affect its ability to become a prestigious school [3]. Classrooms can also enjoy the unrestrained passion. National standards have made explicit regulations on physical education class time and student's time in school. There is no system 
restriction and guarantee. Quality education and lifetime sports are all empty talks.

\section{An analysis of the status quo of college physical education methods}

In higher education, physical education is an indispensable part, and it is also an important stage in the formation of lifelong sports concepts. Therefore, the quality of physical education teaching has a direct impact on the establishment of a person's lifelong sports ideas. Physical education can not only improve the physical fitness of students, but at the same time, after students have mastered certain physical exercise skills, they must also develop good physical exercise and social integration skills, and establish good physical and mental health and moral health. This is also a fundamental prerequisite for a person to enter the society and participate in the work. Therefore, it is self-evident that carrying out physical education among college students in colleges and universities and improving their physical training abilities [3].

\subsection{To replace physical education with physical education teaching, and arouse college students' enthusiasm for physical activity}

Physical education is a very practical curriculum. In physical education teaching, teachers should give students more practice time and pay attention to their practical ability. However, many physical education operations in China's college sports teaching are only demonstrated by teachers in classroom teaching. The main purpose of teaching is to achieve the school's goal for physical education teaching. The classroom teaching is more to teach students some method skills [3]. The consequence of this is that although the students have mastered a lot of physical exercise methods, their practical abilities are not strong, and there are usually less time for self-study in physical education classes, lack of flexibility in physical exercise, too rigid teaching, and the enthusiasm of college students for learning. It's easy to get hit.

\subsection{The excessive emphasis on sports skills, skills teaching, and the continuity of the action ignored}

Due to the influence of the former Soviet Union's sports ideology, Chinese colleges and universities generally emphasize sports skills and skills training for students in physical education. In the student sports classroom, teachers regard physical education and physical development of students as two aspects of the same process, thinking that as long as the students have mastered the sports skills and skills, they can also enhance the physical fitness of the students and achieve physical exercise. The relationship between the practicality of sports skills and the goals of physical education is seen as a subordinate relationship [4]. This is actually a very serious misconception. Over-emphasis on the mastery of motor skills will lead to less coherent movement and poor continuity in physical exercise, which is very detrimental to students' later physical training and learning.

\subsection{The exertion of students' main role ignored, and passive college students' physical exercise}

At present, most colleges and universities in China mainly focus on teachers, classrooms, and teaching materials. They require students to strictly abide by disciplines in the physical education classroom, and teachers are dominant. The purpose of doing so is to ensure the integrity of the teaching process. It is understandable that teachers play a role in imparting knowledge in physical education. However, most physical education workers ignore the fact that students are the main body of learning and the ultimate goal of teaching is to allow students to learn more in the teaching process [4]. All teaching methods and the use of teaching methods must be based on this goal and serve them. Therefore, at the same time of highlighting the main position of physical education teachers, physical education in colleges and universities should respect the students' physical exercise needs, combine the actual needs of students with physical education, and teach students in accordance with their aptitude.

\subsection{Too much attention to uniform teaching from physical education teaching methods}

Due to the influence of traditional teaching, the PE teaching work in Chinese universities put too 
much emphasis on the unity and standardization of the teaching process, the students' personality was suppressed, the stylization phenomenon in the teaching process was serious, and even a lot of times there was a dogmatic teaching style [5]. College students are in adolescence, energetic, and innovative, and this method of physical education will inevitably lead students to resent, and lose interest in physical activity over time. Therefore, Japan's concept of "happy sports" was popular with the majority of students at the beginning of its introduction to China. This idea opposes the compulsory teaching method that over-emphasizes the development of students' personality and ignores students' psychological function in traditional sports teaching, and highlights the importance of student participation. This is also the direction of future physical education reform in Chinese universities.

\section{The improvement measure of college physical education teaching method}

\subsection{The teaching method of physical education from transferring to directing}

For college students, they are willing to participate in sports, but they are not willing to go to physical education classes. In the face of this situation, we need to think deeply and change the current methods of physical education. We will change from teaching-based teaching to instructional teaching. After more than ten years of study, college students already have a certain ability to understand knowledge systems and self-learning skills. Therefore, undergraduates are often tired of too much preaching by teachers in physical education courses, and many movements and skills have been realized by themselves [5]. Teachers are required to make overly detailed action decomposition demonstrations. Therefore, it is necessary for colleges and universities to provide them with a teaching environment that is more attractive to them for physical exercise, so that they can acquire a sense of accomplishment and learning knowledge in the physical education curriculum. To achieve this teaching goal, physical education teachers' first need to change the traditional teaching philosophy, place the students in the main position, and carefully design the physical education content before the course teaching, so that the teaching methods can satisfy most students' physical education learning needs. At the same time, in the teaching, the teacher can also control the entire teaching environment, achieve the expected teaching goals and teaching effects, and cannot let students, regardless of disregard. For students with different basics, they should be guided separately, instead of using a unified teaching to explain, disrupting the learning progress of other students, highlighting the flexibility in physical education, changing the mechanical teaching model, and stimulating students' enthusiasm for physical exercise [5].

\subsection{Methodological skills to learning methods}

This should also be the case in college sports teaching. The starting point and end result of physical education should be placed on physical education methods. For example, aerobics teaching is very popular with students. This shows that the sport itself is still attractive. All college students have a beauty-loving psychology. Therefore, aerobics teachers can use this feature to teach students aerobics knowledge in a congenial manner and attract students' attention [6]. They can teach the origin of aerobics culture, play beautiful accompaniment music, and pay attention to movements. For the emotional rendering, so that students are willing to participate in aerobics learning, take the initiative to aerobics sports experience and understanding. This method can be used in the teaching of other sports, so that physical education will not stop at the university. What's more important is that after entering the society, students will still take the initiative to learn and exercise, and serve the purpose of lifelong sports.

\subsection{To deepen the reform of physical education teaching and highlight the main position of students}

In the reform process of higher education, schools should give prominence to the students' main body position and thoroughly implement the "student subject" ideology, instead of focusing on this idea only at the superficial level and implementing them in specific practical teaching. This requires 
teachers to prepare well before teaching [6]. In the physical education classroom, we must follow the teaching philosophy of "students as the mainstay and teachers as the supplements", so that students can feel free and flexible in physical education so that they can really train students. Exercise hobby, develop the habit of exercising for life.

\subsection{To streamline sports teaching materials and reduce the teaching of sports teaching}

If there are many sports teaching materials for college students, then teachers will be busy with the task of teaching. For all physical education content, it can only be a simple explanation. Students cannot truly understand the knowledge and skills taught by teachers, and it is difficult to obtain a sense of achievement. As a result, students will become bored and lose their physical exercise [7]. Therefore, during the new course improvement process, it is necessary to delete those unnecessary knowledge contents and grasp the teaching focus. At the same time, the physical education teachers must also enrich their own knowledge system and flexibly conduct physical education so that the students can really apply what they have learned. Physical exercise really generates interest, so that after going out of school, you can also continue to exercise [7].

\subsection{To reform the evaluation method system of physical education teaching in colleges and universities}

Evaluation of physical education will directly affect the development of physical education teaching in higher education in China. Only by establishing a scientific, rational and efficient evaluation system of physical education teaching can the Chinese college sports reform succeed. The evaluation of physical education teaching has the function of value judgment and feedback teaching quality. It plays a dominant role in physical education in colleges and universities. The physical education teaching evaluation method system must really come out from the previous evaluation model and apply the modern digital technology to the evaluation of physical education teaching [7]. Go and establish a high-quality teaching evaluation method that meets the needs of sports development in Chinese universities.

\section{Summary}

In short, college sports teaching methods have a crucial influence on the physical exercise of college students. If colleges and universities want to promote the reform of physical education teaching, we must change the concept of physical education and use new physical education methods. In the new era of physical education must pay attention to "people-oriented" thinking, the students as the main body of physical education, inspire students interest in sports and hobbies, so that they can develop the habit of conscious exercise. Students' ideological awareness of establishing lifelong fitness will also benefit them for life. Having a healthy and strong body can lead to more work and life.

\section{References}

[1] X.L. Pan, Analyzes the cultivation of college students' sports consciousness, Sports world, 2008, vol.11, pp.58-60.

[2] Sh. T. Hao, Research on the influence of college physical education organization Form on College Students' Participation in Physical Exercise, Contemporary Sports Science and Technology, 2014, vol.9, pp.97-99.

[3] X. Zh. Zhang and Q.H. Zhong, Some theoretical problems in school physical education curriculum resources, Journal of Northwest Normal University: Natural Science Edition, 2005, vol.1, pp.9-11.

[4] J.X. Zhao, Several Measures of Heuristic Teaching, Ningxia Education, 2006, vol.2, 12-19.

[5] Y.T. Zhou and H.T. Zhao, discusses how to use heuristics for physical education, Liaoning Sports 
Science and Technology, 2002, vol.2, pp.32-35.

[6] H.T. Huang, Reflections on subject and subjective teaching in physical education, Exercise, 2011, vol.14, pp.102-103.

[7] Zh.Ch. Wu, Modern teaching theory and physical education, Journal of Northwest Normal University: Natural Science Edition, 2010, pp.60-62. 